Check for updates

Cite this: RSC Adv., 2018, 8, 34937

\title{
Mesophase behavior of new linear supramolecular hydrogen-bonding complexes $\uparrow$
}

\begin{abstract}
H. A. Ahmed, (D) *ab M. Hagar ${ }^{\text {ac }}$ and A. Aljuhani ${ }^{d}$
Thermal and mesophase behavior of four new series of hydrogen-bonded supramolecular complexes (In/ $\mathrm{IIm}$ ) were investigated by differential scanning calorimetry and phases identified by polarized light microscopy. All hydrogen-bonded complexes formed from 4-alkoxyphenylazobenzoic acid (In) and 4(4'-pyridylazophenyl)-4"-alkoxybenzoates $(\mathrm{IIm})$. The results revealed that the prepared complexes are dimorphic, possessing smectic $C$ and nematic phases. The comparison, made between the present series and previously investigated simpler, $\mathrm{In} / \mathrm{III} m$ and angular, $\mathrm{In} / \mathrm{IV} \mathrm{m}$ analogues, revealed that increasing the length of the mesogenic core and/or linearity of complex increase the stabilities of both the smectic $\mathrm{C}$ and nematic phases.
\end{abstract}

Received 15th September 2018

Accepted 4th October 2018

DOI: $10.1039 / \mathrm{c} 8 \mathrm{ra} 07692 \mathrm{~h}$

rsc.li/rsc-advances

pyridines and benzoic acids moieties was used to induce

\section{Introduction}

Mesomorphic properties of liquid crystal materials are largely affected by any change in their molecular structure. Several methods were reported to obtain highly stable nano structured systems from anisotropic particles and liquid crystals such as stable colloidal dispersions of halloysite clay nanotubes..$^{1-3}$ Hydrogen bonding between carboxyl and pyridyl moieties proved to be extremely fruitful for the formation of supramolecular hydrogen-bonded liquid crystals (SMHBLCs). ${ }^{4-7}$ Thus, intermolecular hydrogen-bond interactions have shown great potential in the preparation of new liquid crystalline systems, especially in thermotropic liquid crystals. $^{8-12}$ Extensive researches have been focused on the field of hydrogen-bonded liquid crystalline complexes. ${ }^{13-18}$ Most of the SMHLCs studied are based on the rod-like intermolecular hydrogen-bonding ${ }^{19-25}$ and there is much interest towards the formation of angular supramolecular hydrogen bonded liquid crystals..$^{15}$ The concept of SMHLCs has been successively applied in many applications in scientific and technological fields. ${ }^{26-30}$ Number of hydrogenbonded binary systems, based on pyridine as proton acceptors and carboxylic acid derivatives as the proton donors, have been investigated and reviewed and reviewed extensively., ${ }^{531-36}$ More recently, hydrogen-bonding between

${ }^{a}$ College of Sciences, Chemistry Department, Taibah University, Yanbu, Saudi Arabia. E-mail:hmahmoud@taibahu.edu.sa; ahoda@sci.cu.edu.eg; mohamedhaggar@gmail. com

${ }^{b}$ Faculty of Science, Department of Chemistry, Cairo University, Cairo, Egypt

${ }^{c}$ Faculty of Science, Chemistry Department, Alexandria University, Alexandria, Egypt ${ }^{d}$ Faculty of Sciences, Chemistry Department, Taibah University, Al-Madinah alMunawwarah, Saudi Arabia. E-mail: ateyatallah@hotmail.com

$\dagger$ Electronic supplementary information (ESI) available. See DOI: $10.1039 / \mathrm{c} 8 \mathrm{ra0} 67692 \mathrm{~h}$ nematic, smectic and columnar mesophases. ${ }^{5,37,38}$ On the other hand, the azobenzene units are of special interest due to their ability for trans-cis-isomerization upon irradiation with UV light. In supramolecular azo-based liquid crystals, via hydrogen bonding interaction, the rigid-rod core is lengthened, and thus induces liquid crystalline behaviour that may not occur in the individual components. ${ }^{39,40}$ Such induced mesomorphic behaviour is attributed to the formation of the elongated hydrogen-bonded complex. Moreover, the induction of liquid crystalline character is also associated with the strength of hydrogen bonds formed between the interacting components. This would accordingly be affected by the change in polarity and/or polarisability of both components.

Continuing our work, the present study is to investigate the thermal behavior resulting from intermolecular hydrogen-bond formation between the 4-alkoxyphenylazobenzoic acids, ${ }^{41,42} \mathbf{I} n$, and 4-(4'-pyridylazophenyl) $4^{\prime \prime}$-alkoxybenzoates, ${ }^{19}$ II $m$. Therefore, we constructed all possible $1: 1$ supramolecular complexes $\mathbf{I} n / \mathbf{I I} m$ with various lengths of the terminal alkoxy chains in order to monitor the effect of similar and/or different proportionating of alkoxychain length on the mesophase formation, shown in Scheme 1. Also investigated, the effect of introducing additional azobenzene unit to the linear supramolecular complexes previously reported ${ }^{19}$ through hydrogen-bond formation between 4 -alkoxy benzoic acids (III $n$ ) as proton donors and 4-(4'-pyridylazophenyl) 4 "-alkoxybenzoates (II $m$ ) as proton acceptors (III $n / \mathbf{I I} m)$. A comparison was made, also between the present series (I $n / \mathbf{I} \mathrm{m})$ and previously investigated angular isomer, $\mathbf{I} n / \mathbf{I V} m,{ }^{\mathbf{1 5}}$ to investigate the effect of the linearity of the structure on the mesophase stability. 
<smiles>CCOC(=O)c1ccc(N)cc1</smiles>

1) $\mathrm{NaNO}_{2} / \mathrm{HCl}$

2) $\mathrm{Phenol} / \mathrm{NaOH}$<smiles>CCOC(=O)c1ccc(NNc2ccc(O)cc2)cc1</smiles>

1<smiles>[R]C(O)CCCCC</smiles>

$\mathrm{C}_{\mathrm{n}} \mathrm{H}_{2 \mathrm{n}+1} \mathrm{O}$<smiles>CCOC(=O)c1ccccc1</smiles><smiles>O=C(O)c1ccc(I)cc1</smiles>

KOH/Aq.ethanol reflux for $24 \mathrm{~h}$<smiles>N=Nc1ccc(OCCO)cc1</smiles>

In

Scheme 1 Preparation of 4-alkoxyphenylazobenzoic acids In.

\section{Experimental}

4-Hexyloxy benzoic acid, 4-octoyloxy benzoic acid, 4-decyloxy benzoic acid and 4-dodecyloxy benzoic acid were obtained from Merck (Germany). N,N'-dicyclohexylcarbodiimide (DCC) and 4dimethylaminopyridine (DMAP) were purchased from Aldrich (Wisconsin, USA). All chemicals were used without further purification. All the solvents used such as dichloromethane, ethanol and methanol were of pure grade and purchased from Aldrich (Wisconsin, USA).
Calorimetric measurements were carried out using a TA Instruments Co. Q20 Differential Scanning Calorimeter (DSC; USA). The DSC was calibrated using the melting temperature and enthalpy of indium and lead. DSC investigation was carried out for small samples $(2-3 \mathrm{mg}$ ) placed in aluminum pans. All measurements were achieved upon heating to stability temperature and cooling to room temperature with heating rate of $10{ }^{\circ} \mathrm{C} \mathrm{min}^{-1}$ in inert atmosphere of nitrogen gas (30 $\mathrm{ml} \mathrm{min}^{-1}$ ) and all transition recorded from the second heating scan.

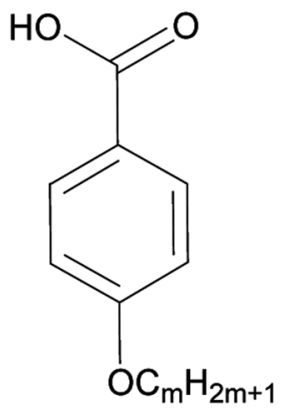<smiles>Oc1ccc(/N=N/c2ccncc2)cc1</smiles>

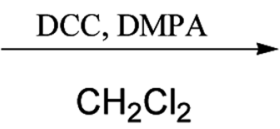<smiles>CCCCCCOc1ccc(C(=O)Oc2ccc(N=Nc3ccncc3)cc2)cc1</smiles>

II $m$ 

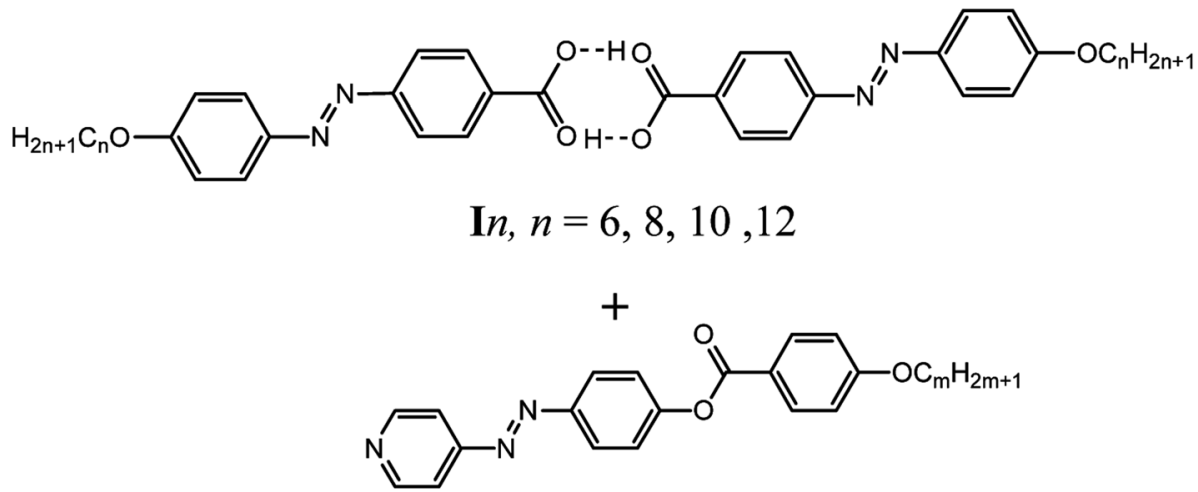

$$
\text { II } m, m=8,10,12,14
$$

(1:1) molar ratio $\begin{aligned} & \text { Melting with stirring then cooling } \\ & \text { to room temperature }\end{aligned}$

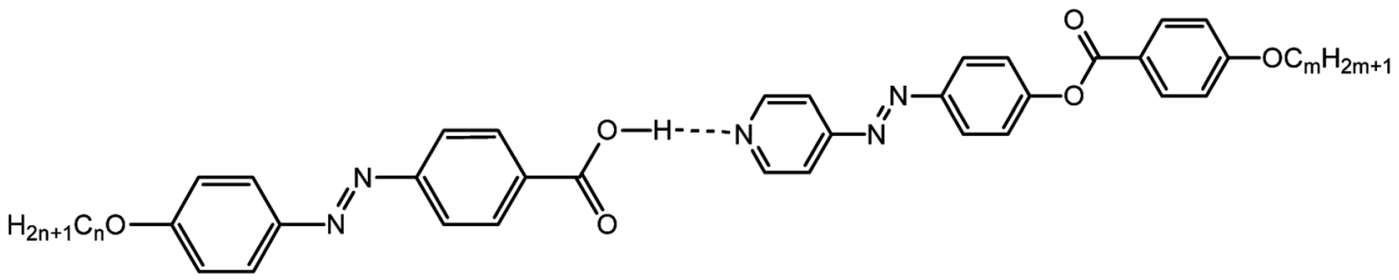

\section{$\mathbf{I} n / \mathbf{I I} m$}

Scheme 3 Preparation of 1 : 1 supramolecular hydrogen-bonded complexes (In/IIm).

Transition temperatures for the individual components and their $1: 1$ associated complexes (I $n / \mathbf{I I} m)$, were determined by DSC, and the types of the mesophase identified by a standard polarized light microscope (PLM, Wild, Germany) attached with Mettler FP82HT hot stage. The temperature is measured by thermocouple attached to the temperature controller. Measurements were made twice and the results have accuracy in transition temperature within $\pm 0.2{ }^{\circ} \mathrm{C}$.

\subsection{Preparation of ethyl 4-hydroxyphenylazobenzoate}

Ethyl 4-aminobenzoate $(0.01 \mathrm{~mol})$ was dissolved in concentrated hydrochloric acid and cooled in ice-salt bath to $0{ }^{\circ} \mathrm{C}$. To the resulting solution, a cold aqueous solution of sodium nitrite (0.03 mol) was added drop-wise with stirring. During the addition, the temperature did not exceed $2{ }^{\circ} \mathrm{C}$. After complete addition, the cold mixture was added drop-wise to an ice-cold solution of phenol $(0.01 \mathrm{~mol})$ in sodium hydroxide $(0.03 \mathrm{~mol})$. The mixture was further stirred at $0{ }^{\circ} \mathrm{C}$ for one hour then acidified with dilute hydrochloric acid. The solid separated was filtered and crystallized twice from ethanol. The product was TLC pure and gave melting point $163{ }^{\circ} \mathrm{C}$ that agreed with that reported in the literature. ${ }^{\mathbf{4 1}}$

\subsection{Preparation of ethyl 4-n-alkoxyphenylazobenzoates}

These were prepared by the method described previously. ${ }^{\mathbf{4 1}}$ Ethyl 4-hydroxyphenylazobenzoate $(0.001 \mathrm{~mol})$ in ethanolic $\mathrm{KOH}(0.02 \mathrm{~mol}, 20 \mathrm{ml})$ to which the appropriate amount of 1bromoalkane $(0.0012 \mathrm{~mol})$ was added drop-wise while stirring. Stirring was continued at room temperature for two days. The solid separated was filtered off, the solution evaporated and the residue crystallized twice from ethanol. The products were TLC pure and give transition temperatures as given in the literature. ${ }^{\mathbf{4 1}}$

\subsection{Preparation of 4-alkoxyphenylazobenzoic acids In}

The esters (2) were hydrolyzed to the corresponding acids by refluxing in aqueous ethanolic potassium hydroxide $(0.02 \mathrm{~mol}$, $20 \mathrm{ml}$ ) for 24 hours then acidified by dilute $\mathrm{HCl}$ to give the corresponding acids. Again the products were crystallized twice from ethanol to give TLC pure solids that give transition temperatures agreeing with those reported in the literature (Scheme 2). ${ }^{\mathbf{4 1 , 4 3}}$

4-[2-[4-(Hexyloxy)phenyl]diazenyl]benzoic acid. Yield $85 \%$, ${ }^{1} \mathrm{H}$ NMR (300 MHz, $\mathrm{CDCl}_{3}$ ): $\delta / \mathrm{ppm}: \delta=8.13(\mathrm{~m}, 2 \mathrm{H}, \mathrm{Ar}-\mathrm{H}), 7.92$ $(\mathrm{m}, 4 \mathrm{H}, \mathrm{Ar}-\mathrm{H}), 7.18(\mathrm{~m}, 2 \mathrm{H}, \mathrm{Ar}-\mathrm{H}), 4.09(\mathrm{t}, J=7.7 \mathrm{~Hz}, 2 \mathrm{H}$, $\left.\mathrm{OCH}_{2} \mathrm{CH}_{2}\right), 1.98-1.74\left(\mathrm{~m}, 2 \mathrm{H}, \mathrm{OCH}_{2} \underline{\mathrm{CH}_{2}}\right), 1.40-1.31(\mathrm{~m}, 6 \mathrm{H}$, 


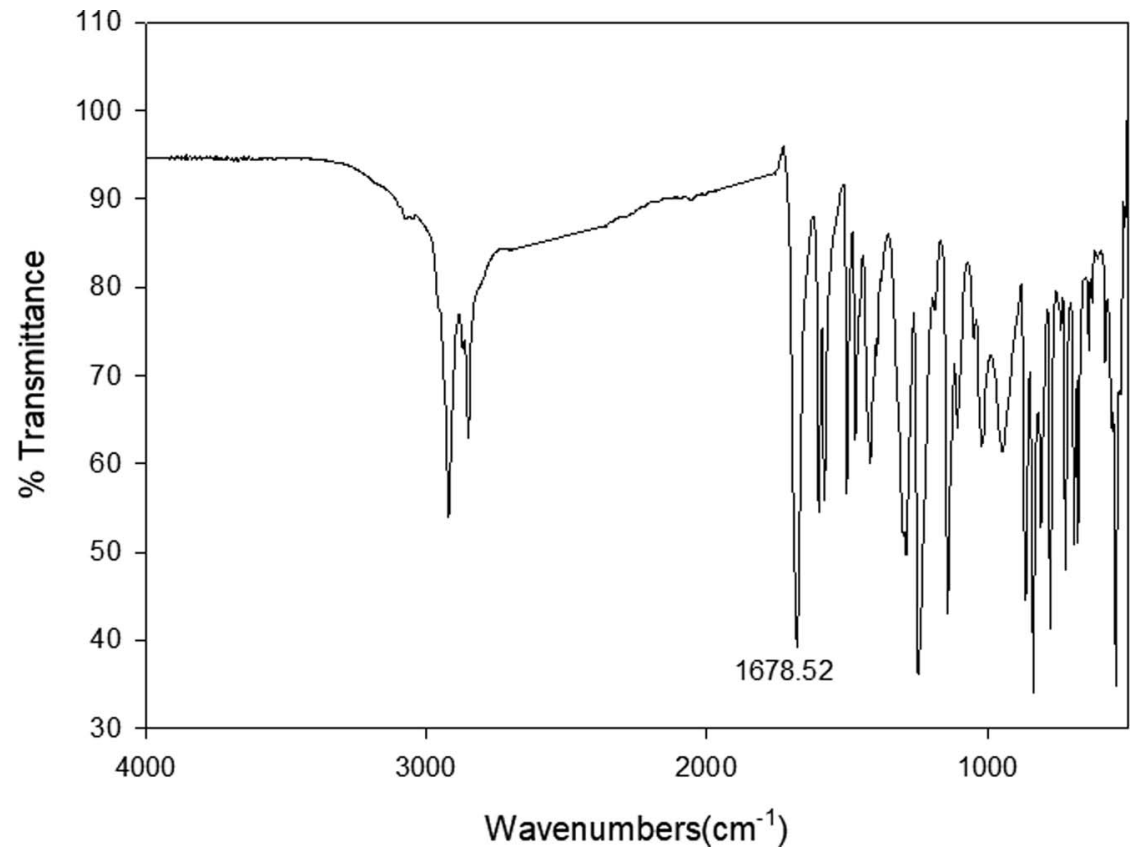

Fig. 1 FTIR spectrum of the 4-decyloxyphenylazobenzoic acid, I10.

$\left.\mathrm{CH}_{2}\right), 0.93\left(\mathrm{t}, J=7.1 \mathrm{~Hz}, 3 \mathrm{H}, \mathrm{CH}_{3}\right)$. Elemental analyses: found (calc.): C, 69.65 (69.92); H, 6.60 (6.79); N, 8.83 (8.58).

\subsection{Preparation of 4-(4'-pyridylazophenyl $) 4^{\prime \prime}$-alkyloxybenzoate IIm}

4-(4'-Pyridylazo)phenol (0.30 g, $1.35 \mathrm{mmol})$ with hexyloxybenzoic acid $(0.30 \mathrm{~g}, 1.35 \mathrm{mmol})$, DCC $(0.28 \mathrm{~g}, 1.35 \mathrm{mmol})$, and few crystals of 4-dimethylaminopyridine (DMAP) as a catalyst, were dissolved in $20 \mathrm{ml} 25 \%$ mixture of $\mathrm{CH}_{2} \mathrm{Cl}_{2}$ and THF(1:3
$\mathrm{CH}_{2} \mathrm{Cl}_{2}$ : THF); the mixture was stirred at room temperature for $48 \mathrm{~h}$. The solid materials were filtered off and the solvent was removed under vacuum. The obtained crude product was purified by recrystallization from ethanol.

4-(4'-Pyridylazophenyl)-4"-hexyloxybenzoate. Yield $77 \%{ }^{1} \mathrm{H}$ $\mathrm{NMR}\left(\mathrm{CDCl}_{3}\right) \delta 8.81(\mathrm{~d}, J=8.3,2 \mathrm{H}, \mathrm{Ar}-\mathrm{H}), 8.17(\mathrm{~d}, J=8.5,2 \mathrm{H}$, $\mathrm{Ar}-\mathrm{H}), 8.05$ (d, $J=8.4,2 \mathrm{H}, \mathrm{Ar}-\mathrm{H}), 7.70(\mathrm{~d}, J=8.5,2 \mathrm{H}, \mathrm{Ar}-\mathrm{H}), 7.43$ $(\mathrm{d}, J=8.5,2 \mathrm{H}, \mathrm{Ar}-\mathrm{H}), 6.70(\mathrm{~d}, J=8.5,2 \mathrm{H}, \mathrm{Ar}-\mathrm{H}), 4.08(\mathrm{t}, J=$

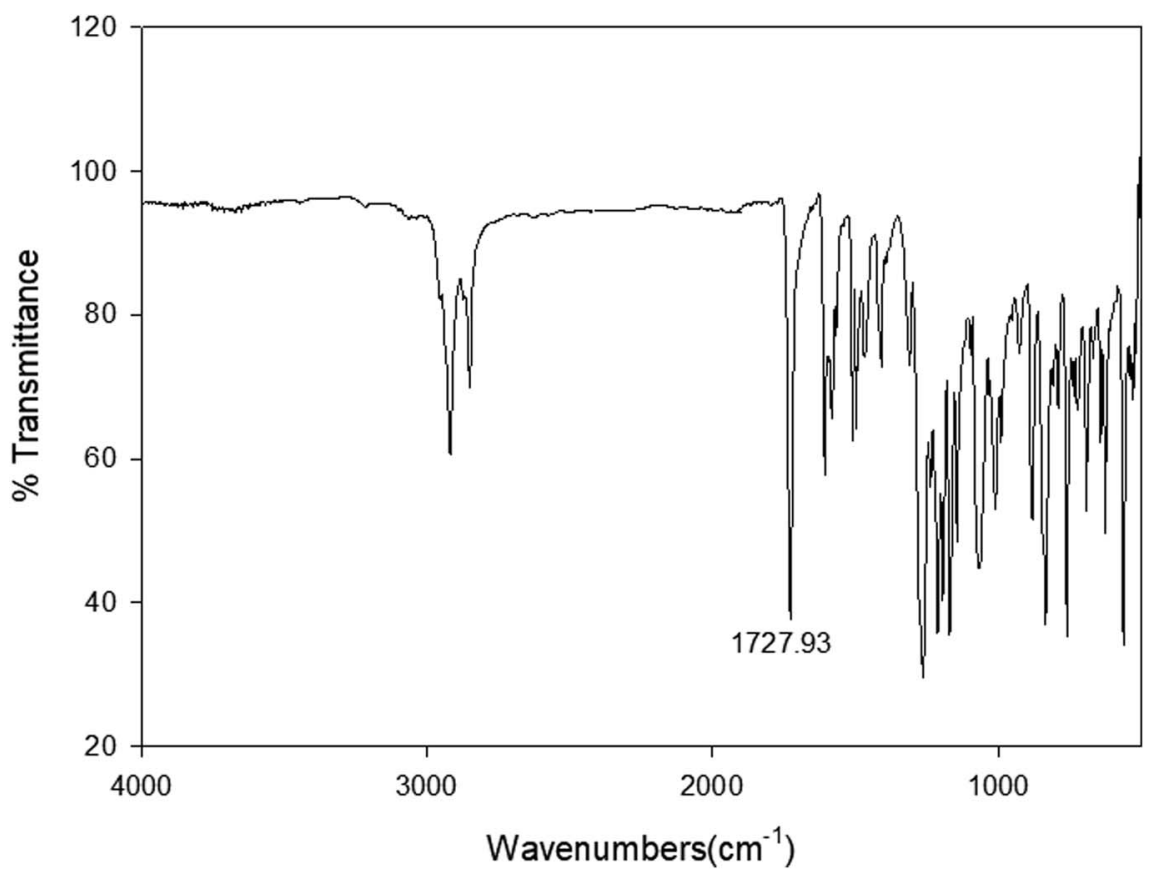

Fig. 2 FTIR spectrum of 4-(4'-pyridylazophenyl)4"-octyloxybenzoate, II8. 


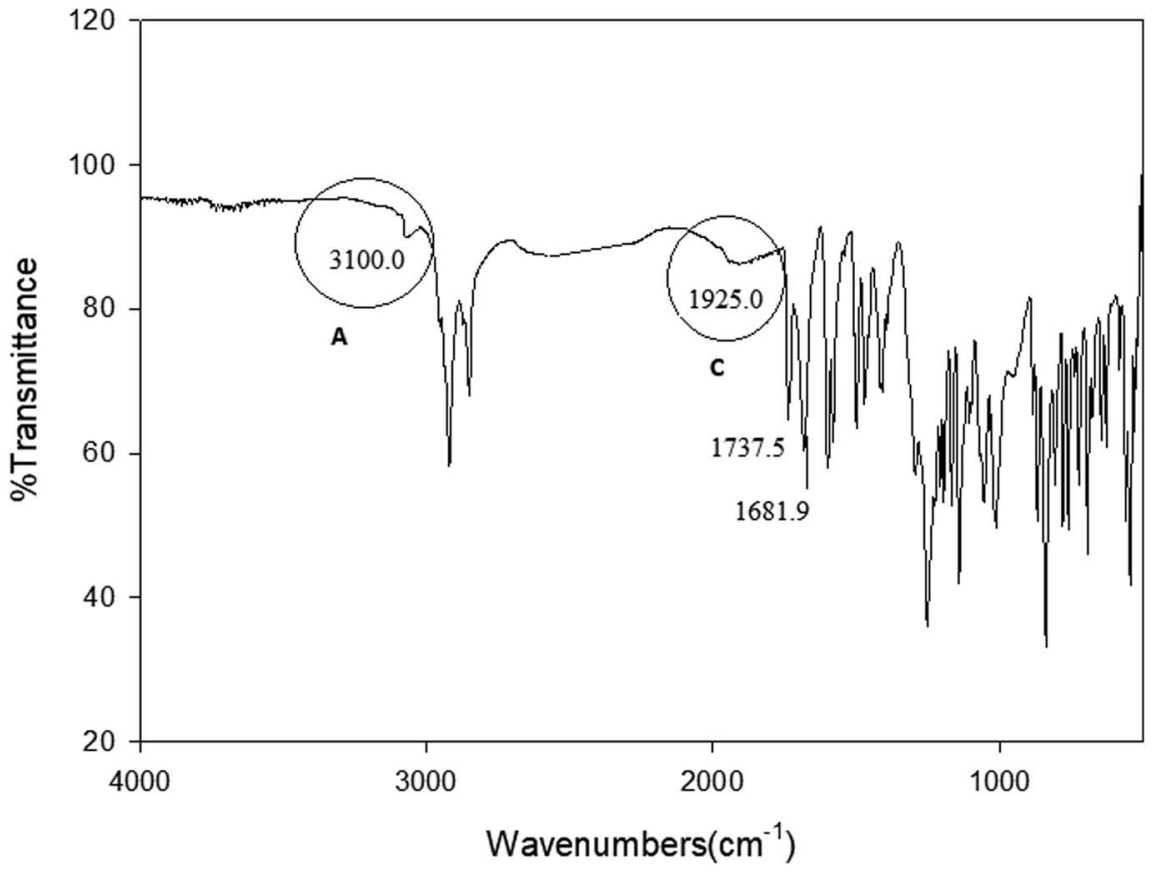

Fig. 3 FTIR spectra of the 1 : 1 supramolecular complex I10/II8.

$\left.6.5 \mathrm{~Hz}, 2 \mathrm{H}, \mathrm{OCH}_{2} \mathrm{CH}_{2}\right), 1.91-1.79\left(\mathrm{~m}, 2 \mathrm{H}, \mathrm{OCH}_{2} \mathrm{CH}_{2}\right), 1.59-1.22$ $\left(\mathrm{m}, 6 \mathrm{H}, \mathrm{CH}_{2}\right), 0.91\left(\mathrm{t}, J=6.8 \mathrm{~Hz}, 3 \mathrm{H}, \mathrm{CH}_{3}\right)$. Elemental analyses: found (calc.): C, 71.76 (71.44); H, 6.63 (6.25); N, 10.22 (10.41).

\subsection{Preparation of supramolecular hydrogen-bonded complexes, In/IIm}

Supramolecular complexes $(\mathbf{I} n / \mathbf{I I} m)$, in the $1: 1$ molar ratios of any two complementary components, were prepared by melting the appropriate amounts of each component, stirring to give an intimate blend and then, cooling with stirring to room temperature (Scheme 3). For example to prepare the supramolecular complex I10/II8: $0.0382 \mathrm{mg}$ of 4-decyloxyphenylazobenzoic acid, I10 and $0.0431 \mathrm{mg}$ of 4 -( $4^{\prime}$-pyridylazophenyl)-4" octyloxybenzoate II8 were mixed together using the method described above.

All diagrams constructed by plotting transition temperatures of the supramolecular hydrogen-bonded complex versus alkoxy-chain length ( $n$ or $m$ ), the symbol "o" denotes crystalmesophase, " " smectic C-to-nematic mesophase and “ $\square$ " nematic-isotropic transitions.

Table 1 Phase transition temperatures $\left({ }^{\circ} \mathrm{C}\right)$, enthalpy of transitions $\left(\mathrm{kJ} \mathrm{mol}^{-1}\right)$ and transition entropies $\left(\mathrm{J} \mathrm{mol}^{-1} \mathrm{~K}^{-1}\right)$, of the $1: 1$ supramolecular complexes $(\mathrm{In} / \mathrm{IIm})^{a}$

\begin{tabular}{|c|c|c|c|c|c|c|c|c|c|}
\hline System & $T_{\mathrm{Cr} 1-\mathrm{Cr} 2}$ & $T_{\mathrm{Cr} 2-\mathrm{SmC}}$ & $\Delta H_{\mathrm{Cr} 2-\mathrm{SmC}}$ & $T_{\mathrm{SmC}-\mathrm{N}}$ & $\Delta H_{\mathrm{SmC}-\mathrm{N}}$ & $\Delta S_{\mathrm{SmC}-\mathrm{N}}$ & $T_{\mathrm{N}-\mathrm{I}}$ & $\Delta H_{\mathrm{N}-\mathrm{I}}$ & $\Delta S_{\mathrm{N}-\mathrm{I}}$ \\
\hline I6/II8 & 106.3 & 153.2 & 37.1 & 230.6 & 5.7 & 12.6 & 245.7 & 3.1 & 6.2 \\
\hline I6/II10 & 91.3 & 149.4 & 40.5 & 232.5 & 3.6 & 7.9 & 244.4 & 3.0 & 5.9 \\
\hline I6/II12 & 126.3 & 136.9 & 29.8 & 231.9 & 3.9 & 8.2 & 236.7 & 2.7 & 5.5 \\
\hline I6/II14 & 118.8 & 133.8 & 32.0 & 229.5 & 2.8 & 5.8 & 235.4 & 2.0 & 3.9 \\
\hline I8/II 8 & 104.4 & 149.4 & 33.8 & 191.0 & 4.1 & 8.8 & 229.4 & 2.8 & 5.6 \\
\hline I8/II10 & 104.0 & 135.0 & 32.9 & 204.4 & 3.0 & 6.3 & 230.0 & 2.2 & 4.3 \\
\hline I8/II12 & 104.4 & 133.2 & 27.2 & 205.6 & 2.1 & 4.4 & 223.0 & 1.8 & 3.6 \\
\hline I8/II14 & 105.0 & 123.5 & 39.0 & 206.8 & 2.9 & 6.0 & 221.3 & 2.1 & 4.2 \\
\hline I10/II8 & 126.3 & 152.5 & 41.1 & 193.0 & 4.6 & 9.9 & 240.7 & 2.3 & 4.5 \\
\hline I10/II10 & 131.9 & 141.9 & 29.5 & 199.0 & 2.0 & 4.2 & 236.1 & 1.7 & 3.3 \\
\hline I10/II12 & 111.3 & 131.9 & 34.5 & 210.0 & 3.6 & 7.5 & 230.0 & 2.3 & 4.6 \\
\hline I10/II14 & 114.2 & 128.2 & 32.8 & 215.6 & 2.5 & 5.1 & 231.3 & 2.0 & 4.0 \\
\hline I12/II8 & 103.1 & 153.6 & 39.7 & 198.0 & 3.8 & 8.1 & 234.4 & 2.4 & 4.7 \\
\hline I12/II10 & 112.5 & 138.8 & 31.9 & 202.0 & 3.7 & 7.8 & 229.3 & 2.7 & 5.4 \\
\hline I12/II12 & 118.1 & 134.4 & 38.2 & 205.0 & 3.1 & 6.5 & 225.0 & 2.2 & 4.4 \\
\hline I12/II14 & 122.0 & 135 & 31.5 & 212.0 & 2.7 & 5.6 & 220.1 & 1.9 & 3.9 \\
\hline
\end{tabular}

${ }^{a}$ Abbreviations: $T_{\mathrm{Cr} 1-\mathrm{Cr} 2}=$ crystal to crystal transition; $T_{\mathrm{Cr} 2-\mathrm{SmC}}=$ crystal to smectic C phase transition; $T_{\mathrm{SmC}-\mathrm{N}}=$ smectic C to nematic transition; $T_{\mathrm{N}-\mathrm{I}}=$ nematic to isotropic liquid transition. $\Delta H_{\mathrm{Cr} 2-\mathrm{SmC}}=$ crystal to smectic C phase transition; $\Delta H_{\mathrm{SmC}-\mathrm{N}}=$ smectic C to nematic transition; $\Delta H_{\mathrm{N}-\mathrm{I}}=$ nematic to isotropic liquid transition; $\Delta S_{\mathrm{SmC}-\mathrm{N}}=$ smectic C to nematic transition; $\Delta S_{\mathrm{N}-\mathrm{I}}=$ nematic to isotropic liquid transition. 

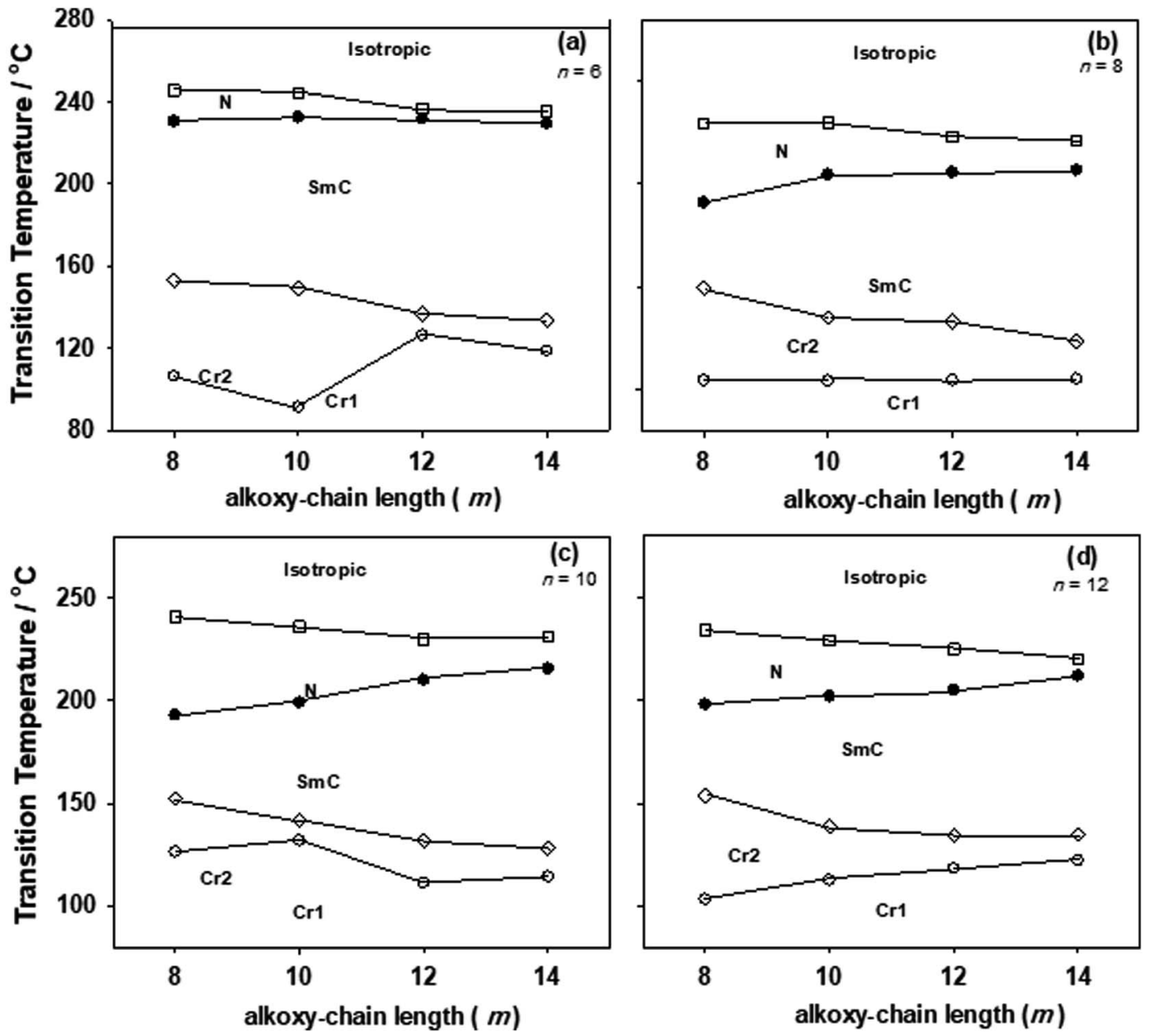

Fig. 4 Effect of the alkoxy-chain length $(m)$ of the pyridine-based derivatives (IIm) on mesophase behavior of the $1: 1$ supramolecular hydrogenbonded complexes, (a) $n=6$; (b) $n=8$; (c) $n=10$ : (d) $n=12, T_{\mathrm{cr} 1-\mathrm{Cr} 2}=$ crystal 1 to crystal 2 transition (O); $T_{\mathrm{cr} 2-\mathrm{Smc}}=\mathrm{crystal} 2$ to smectic $C$ phase transition $(\diamond) ; T_{\mathrm{SmC}-\mathrm{N}}=$ smectic $C$ to nematic transition $(\mathbf{O}) ; T_{\mathrm{N}-1}=$ nematic to isotropic liquid transition $(\square)$.

\subsection{Structural confirmation}

The purity of the prepared compounds were checked with thinlayer chromatography using TLC-sheets coated with silica gel (E. Merck), whereby single spots were detected by a UV-lamp.

The molecular formulae of the prepared compounds were confirmed via elemental analyses, infrared, ${ }^{1} \mathrm{H}-\mathrm{NMR}$, and mass spectroscopy. The results agreed, within the permissible limits, with the proposed structures and with those reported in the literature..$^{\mathbf{1 5}, 19}$

The formation of the supramolecular complexes $(\mathbf{I} n / \mathbf{I I} m)$ were confirmed by DSC investigation as well as Fourier Transform Infrared Spectroscopy (FTIR), which carried out using Nicolet is 10 Thermo scientific.

\section{Results and discussion}

\subsection{Fourier transform infrared spectroscopy (FTIR)}

Infrared spectra measurements were performed for the individual components i. e. 4-alkoxyphenylazo benzoic acids (In) and 4-( $4^{\prime}$-pyridylazophenyl $4^{\prime \prime}$-alkoxybenzoates (II $m$ ) as well as to their supramolecular complexes $(\mathbf{I} n / \mathbf{I I} m)$. For example, the IR spectrum of $\mathbf{I} 10$ and II8 are given in Fig. 1 and 2, respectively.
The infrared absorption spectra for all the homologues $(\mathbf{I} n)$ were found to be identical with the mesomeric shift of the carboxylic carbonyl which attributed to the peak at $1678.5 \mathrm{~cm}^{-1}$. Therefore, the alkoxy-chain length $(n)$ has no significant effect on the wave number of the peaks. This specific band shows that the carboxylic acid exists in the dimer form shown in Scheme 3 via intermolecular hydrogen bonding between the carboxylic groups. ${ }^{19}$ Similarly, the spectral data of the proton acceptors, II $m$, shows that the alkyl chain length has again no effect on the observed IR spectra for a given homologues series. In order to confirm the formation of the supramolecular complexes, $\mathbf{I} n / \mathbf{I I} m$, IR spectra for the prepared complexes were measured. Fig. 3 shows the IR spectra of the complex I10/II8 prepared from equal molar amounts of $\mathbf{I} 10$ and II8. A comparative IR spectra of I10, II8, and I10/II 8 is shown in Fig. 3. It had been reported that ${ }^{\mathbf{4 3 - 4 7}}$ the carbonyl stretching region as well as the Fermi resonance vibration bands (A-type, $3100 \mathrm{~cm}^{-1}$; C-type, $1925 \mathrm{~cm}^{-1}$ ) in the spectra of the complex is an important evidence of intermolecular hydrogen bonding, where, the lower wave number $(\dot{u}=$ $1678.5 \mathrm{~cm}^{-1}$ ) of $\mathrm{C}=\mathrm{O}$ group stretching vibration of the cyclic carboxylic acid is shifted to a higher wave number ( $\dot{u}=$ $1681.9 \mathrm{~cm}^{-1}$ ) of the hydrogen-bonded dimers. 

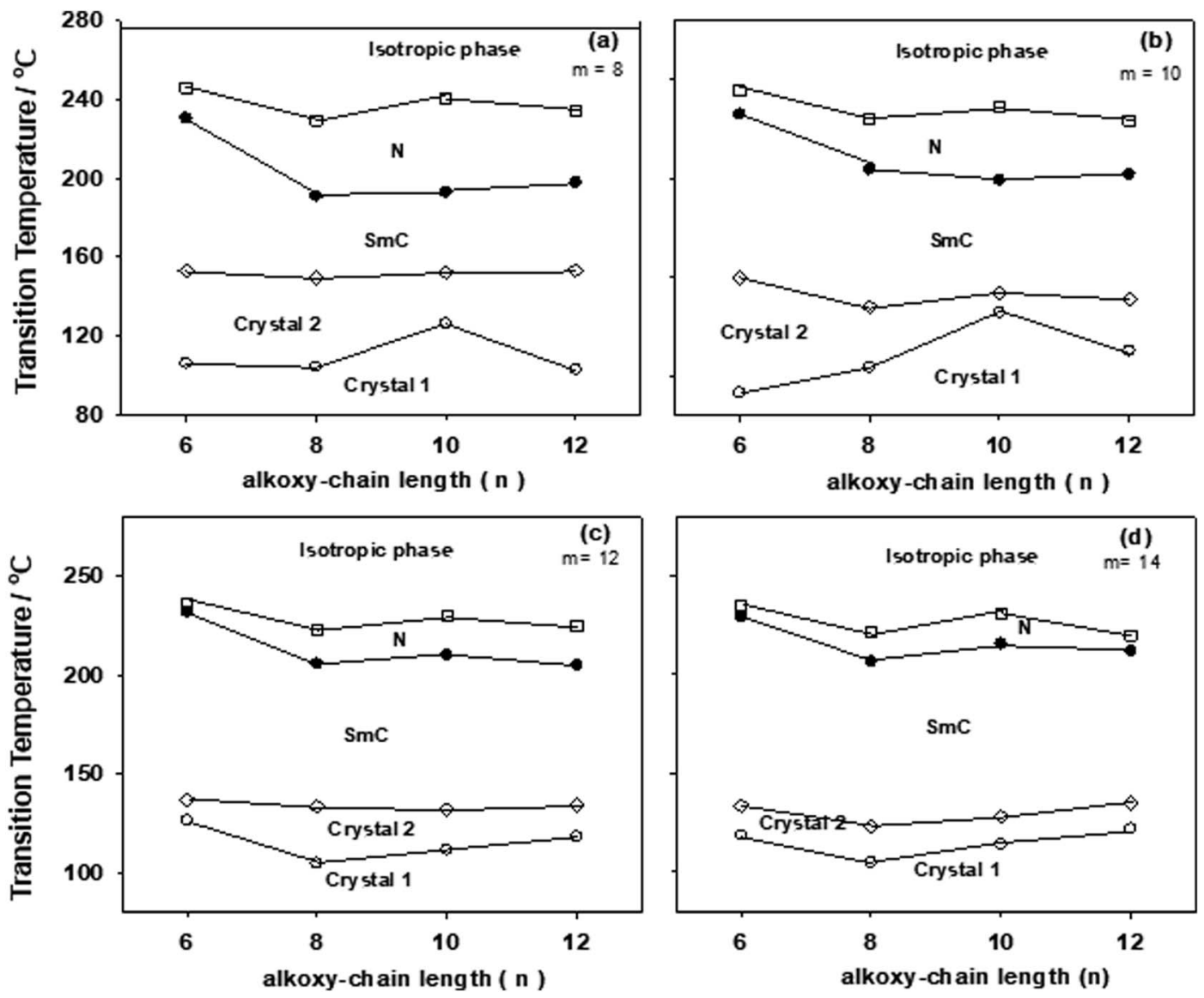

Fig. 5 Effect of the alkoxy-chain length $(n)$ of the pyridine-based derivatives (In) on mesophase behavior of the $1: 1$ supramolecular hydrogenbonded complexes, (a) $m=8$; (b) $m=10$; (c) $m=12$ : (d) $m=14, T_{\mathrm{Cr} 1-\mathrm{Cr} 2}=$ crystal 1 to crystal 2 transition ( $O$ ); $T_{\mathrm{Cr} 2-\mathrm{Smc}}=\mathrm{crystal} 2$ to smectic $\mathrm{C}$ phase transition $(\diamond) ; T_{S m C-N}=$ smectic $C$ to nematic transition $(\bullet) ; T_{N-1}=$ nematic to isotropic liquid transition ( $\square$ ).

3.2. Phase behavior of $1: 1$ molar mixtures as a function of the alkoxy-chain length

The phase behavior of the prepared complexes $\mathbf{I} n / \mathbf{I I} m$ was investigated by PLM and DSC. PLM was used to detect phase transition temperatures as well as textures of the liquid crystal phases exhibited by the complexes I $n / \mathbf{I I} \mathrm{m}$. PLM observations were verified by the DSC measurements and types of mesophases were identified for all prepared supramolecular complexes $\mathbf{I} n / \mathbf{I I} m$.

It should be mentioned that, the mesophase behavior of the prepared 4-alkoxy phenylazo-benzoic acids $\mathbf{I} n$ exhibit smectic $\mathrm{C}$ phase (SmC) with relatively high transition temperatures and nematic phase with very small range, ${ }^{\mathbf{1 5 , 4 1}}$ while the azopyridines II $m$ exhibit smectic A phase (SmA) except the lower chain compound II8 is dimorphic possessing SmA and nematic phases. ${ }^{19}$ Therefore, it was interesting to investigate the phase behavior of the complexes resulting from mixing compounds I $n$ and II $m$.

Transition temperatures and their corresponding values of transition enthalpies, as measured by DSC, for the 1:1 molar supramolecular complexes $\mathbf{I} n / \mathbf{I I} m$ are collected in Table 1. All transition temperatures were represented graphically once as a function of alkoxy-chain length $(n)$ on the acid complement and another against $(m)$ on the pyridine-based complement in Fig. 4 and 5; respectively. As can be seen from Table 1, Fig. 4 and 5, independent of either $n$ or $m$ of the acid and base components, smectic $\mathrm{C}$ and nematic mesophases are exhibited by all complexes in addition to, two crystalline phases given as $\mathrm{Cr} 1$ and $\mathrm{Cr} 2$. It can also be seen from Fig. 4 that the nematic phase range decreases gradually with the increase of the acid alkoxy-chain length $(n)$. SmC phase range is increasing with increasing the acid alkoxy-chain length $(n)$ and decreases gradually with the increase of base alkoxy-chain length $(m)$.

Fig. 4 showed that for a given value of $m$, the melting temperatures of the supramolecular complexes are slightly affected by the alkoxy-chain length of the acid complement $(n)$. Therefore, the acid $\mathbf{I} n$ or the azo-pyridine II $m$ components exhibit very small range of $\mathrm{N}$ phase, the resulted complexes $\mathbf{I} n$ / II $m$ constructed via intermolecular hydrogen bond showed an nematic phase with relatively wide range. Representative examples of polarizing optical microscopic images of the mesophases are shown in Fig. 6. Fig. 6 show images of SmA phase of azo-pyridine II8, SmC phase and schlieren texture of nematic phase of the dimorphic complex I10/II8. 

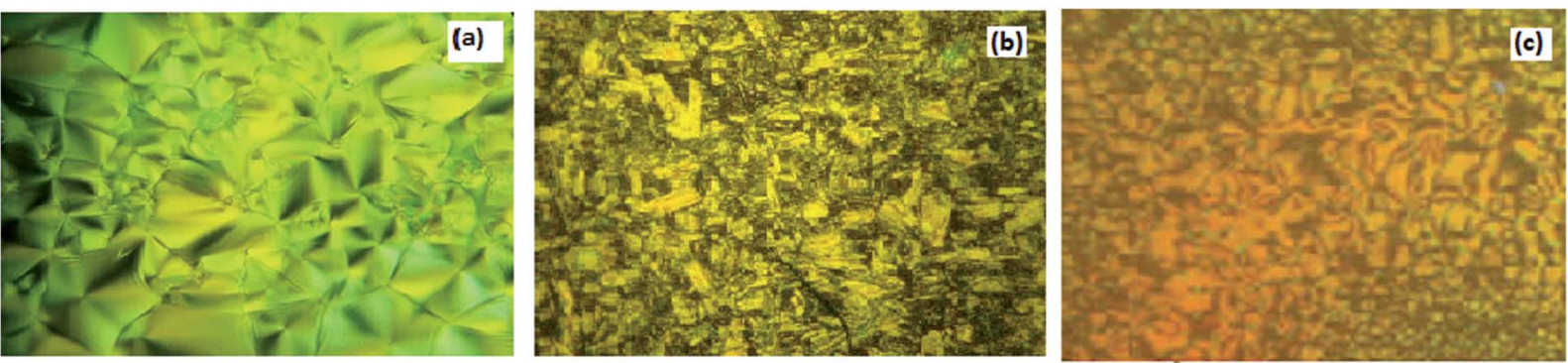

Fig. $6 \mathrm{PLM}$ textures of (a) SmA phase of II8 at $105.0^{\circ} \mathrm{C}$; (b) SmC phase of complex I10/II8 at $183.0^{\circ} \mathrm{C}$; and (c) nematic phase of the complex I10/ 118 at $225.0^{\circ} \mathrm{C}$.

3.3. Effect of the extra phenylazo group on the mesophase behaviour of the supramolecular hydrogen-bonded complexes

In order to investigate the effect of incorporating an extra phenylazo group to molecules of the simple 4-alkoxybenzoic acids (III $n)$ on their mesophase behaviour of $1: 1$ molar mixtures with the 4 -( $4^{\prime}$-pyridylazophenyl $) 4^{\prime \prime}$-alkoxybenzoates (III $n / \mathbf{I I} m)$, a comparison was made between the mesophase stabilities $\left(T_{\mathrm{C}}\right)$ of 4- $n$-alkoxyphenylazo benzoic acids (I $\left.n\right)$ supramolecular hydrogen-bonded complexes $(\mathbf{I} n / \mathbf{I I} \mathrm{m})$ and their corresponding 4- $n$-alkoxy benzoic acids (III $n / \mathbf{I I} m){ }^{19}$ as a function of alkoxy-chain length $(n)$ and represented graphically in Fig. 7. The study revealed that increasing the length of the mesogenic core by a phenylazo moiety resulted in an increase of the stability of both the smectic and nematic mesophases. In addition, the SmC mesophase range observed in the present investigated mixtures $\mathbf{I} n / \mathbf{I I} m$ has been increased upon incorporation of the phenylazo group in III $n / \mathbf{I I} m$.

\subsection{Comparison between isomeric linear and angular} supramolecular hydrogen-bonded complexes

It is interesting to compare the mesophase stability $\left(T_{\mathrm{C}}\right)$ of the present series of linear supramolecular complexes $(\mathbf{I} n / \mathbf{I I} m)$ with the previously investigated angular complexes $(\mathbf{I} n / \mathbf{I V} m)$ in which only the base complement (II $m)$ is replaced by the 4 - $\left(3^{\prime}\right.$-pyridylazophenyl) $4^{\prime \prime}$-alkoxybenzoates, IV $m \cdot{ }^{15}$ In such a comparison, the effect of a modification will be investigated on the stability of the mesophase $\left(T_{\mathrm{C}}\right)$ as well as the type of mesophase observed. Fig. 8 represents the $T_{\mathrm{C}}$ dependencies on the alkoxychain length $(n)$ attached to the common 4- $n$-alkoxyphenylazo benzoic acid complement (I $n$ ) for these two, linear and angular, complexes.

\subsection{Entropy changes}

The entropies of the smectic C-to-nematic and nematic-toisotropic transitions were estimated for all the $1: 1$ supramolecular hydrogen-bonded complexes $(\mathbf{I} n / \mathbf{I I} m)$, and the results are appended to Table 1 . As seen from Table 1, independent of the length of the alkoxy-chains ( $n$ or $m$ ), all entropies of $\mathrm{N}-\mathrm{I}$ transitions $\left(\Delta S_{\mathrm{N}-\mathrm{I}}\right)$ are of lower values than those of the corresponding $\Delta S_{\text {SmC-N }}$ transitions. The decrease observed in $\Delta S_{\mathrm{N}-\mathrm{I}}$ is presumably a reflection of the increase in the biaxiality of the mesogenic group, resulted in the flexible terminal alkoxy-chain, being less strongly anchored at its end, giving the resulting decrease in conformational entropy. ${ }^{40}$ This dependency

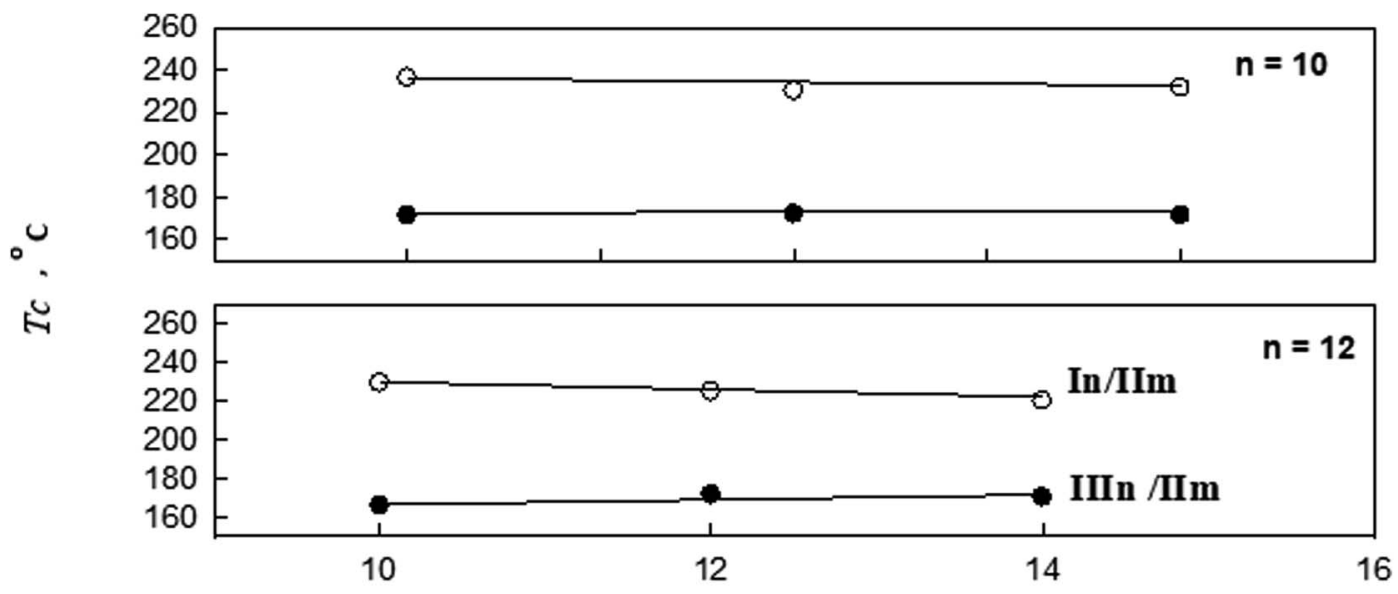

\section{Alkoxy chain-length ( $\mathrm{m}$ )}

Fig. 7 Effect of alkoxy-chain length $(\mathrm{m})$ on mesophase behavior of the $\mathrm{In} / \mathrm{IIm}$ and IIIn/IIm 1 : 1 supramolecular complexes. 




\section{Alkoxy chain-length ( $\mathrm{m}$ )}

Fig. 8 Effect of alkoxy-chain length $(m)$ on mesophase behavior of the $\mathrm{I} n / \mathrm{II} m$ and $\mathrm{I} n / \mathrm{IV} m$ supramolecular complexes.

indicates that the length of the terminal substituents, whether on the acid $(n)$ or the base $(m)$ complements, has led to an irregular $\Delta S_{\mathrm{N}-\mathrm{I}}$. An explanation that the entropies do not correlate well with either of the two terminal alkoxy-chain length ( $n$ or $m$ ), may be related to the irregular change of lateral adhesion upon the increase of the total molecular length. ${ }^{48}$

\section{Conclusion}

New types of $1: 1$ hydrogen-bonded supramolecular complexes were prepared. The formation of complexes via intermolecular hydrogen bond between the complementary components was confirmed by DSC and FTIR spectroscopy. It was found that, their supramolecular complexes I $n / \mathbf{I I} m$ exhibit relatively high range nematic phase in addition to the SmC phase. Moreover, the nematic phases are exhibited by all complexes regardless of the length of the terminal alkoxy chains either on the proton donor $\mathbf{I} n$ or the proton acceptor II $m$. A comparison was made between the present series of complexes and the previously investigated angular, I $n / \mathbf{I V} m$, and simple linear, III $n / \mathbf{I I} m$, analogues, revealed that increasing the length of the mesogenic core, by inclusion of a phenylazo moiety, increases the stabilities of both the smectic $\mathrm{C}$ and nematic mesophases. It was also observed that the entropy change vary irregularly with either of the alkoxy-chain length $n$ or $m$.

\section{Conflicts of interest}

The authors declare no conflict of interest.

\section{Acknowledgements}

Authors gratefully acknowledge the Deanship of Scientific Research, Taibah University for the support of this research work, research group No. 60333.

\section{References}

1 A. A. E. Sakr, T. Zaki, O. Elgabry, M. A. Ebiad, S. M. El-Sabagh and M. M. Emara, Appl. Clay Sci., 2018, 160, 263-269.

2 S. Dutt, P. F. Siril and S. Remita, RSC Adv., 2017, 7, 57335750 .

3 L. Lisuzzo, G. Cavallaro, F. Parisi, S. Milioto and G. Lazzara, Ceram. Int., 2018. 
4 D. Demus, J. W. Goodby, G. W. Gray, H. W. Spiess and V. Vill, Low Molecular Weight Liquid Crystals I: Calamitic Liquid Crystals, Handbook of Liquid Crystals, vol. 2A, John Wiley \& Sons, 2011.

5 C. M. Paleos and D. Tsiourvas, Liq. Cryst., 2001, 28, 11271161.

6 C. M. Paleos and D. Tsiourvas, Angew. Chem., Int. Ed. Engl., 1995, 34, 1696-1711.

7 M. Naoum, A. Fahmi and M. Alaasar, Mol. Cryst. Liq. Cryst., 2008, 482, 57-70.

8 T. Kato and J. M. Frechet, J. Am. Chem. Soc., 1989, 111, 85338534.

9 T. Kato and J. M. Frechet, Macromolecules, 1989, 22, 38183819.

10 A. J. Thote and R. B. Gupta, Ind. Eng. Chem. Res., 2003, 42, 1129-1136.

11 M.-J. Brienne, J. Gabard, J.-M. Lehn and I. Stibor, J. Chem. Soc., Chem. Commun., 1989, 1868-1870.

12 H. Ahmed, M. Hagar, M. Alaasar and M. Naoum, Liq. Cryst., 2018, 1-10.

13 J. W. Goodby, R. J. Mandle, E. J. Davis, T. Zhong and S. J. Cowling, Liq. Cryst., 2015, 42, 593-622.

14 D. Janietz and M. Bauer, Macromol. Chem. Phys., 1991, 192, 2635-2640.

15 H. Ahmed and M. Naoum, Liq. Cryst., 2016, 43, 222-234.

16 M. Fouzai, R. Hamdi, S. Ghrab, T. Soltani, A. Ionescu and T. Othman, J. Mol. Liq., 2018, 249, 1279-1286.

17 M. Alaasar, S. Poppe, Q. Dong, F. Liu and C. Tschierske, Chem. Commun., 2016, 52, 13869-13872.

18 H. K. Bisoyi and Q. Li, Chem. Rev., 2016, 116, 15089-15166.

19 M. Naoum, A. Fahmi and M. Alaasar, Mol. Cryst. Liq. Cryst., 2008, 487, 74-91.

20 M. Okumuş and Ş. Özgan, Liq. Cryst., 2014, 41, 1293-1302.

21 A. Ashok Kumar, B. Sridevi, M. Srinivasulu, P. Chalapathi and D. Potukuchi, Liq. Cryst., 2014, 41, 184-196.

22 J. R. Wolf, T. Zhao, C. Landorf and D. J. Dyer, Liq. Cryst., 2014, 41, 721-730.

23 S. Sreehari Sastry, K. Lakshmi Sarada, K. Mallika, C. Nageswara Rao, S. Lakhminarayana and H. Sie Tiong, Liq. Cryst., 2014, 41, 1483-1494.

24 M. D. Miranda, F. V. Chávez, T. M. Maria, M. E. S. Eusebio, P. Sebastião and M. R. Silva, Liq. Cryst., 2014, 41, 1743-1751.

25 D. A. Paterson, A. Martínez-Felipe, S. M. Jansze, A. TM Marcelis, J. MD Storey and C. T. Imrie, Liq. Cryst., 2015, 42, 928-939.
26 R. Dong, Y. Zhou, X. Huang, X. Zhu, Y. Lu and J. Shen, Adv. Mater., 2015, 27, 498-526.

27 Y. Yang and M. W. Urban, Chem. Soc. Rev., 2013, 42, 74467467.

28 K. Liu, Y. Kang, Z. Wang and X. Zhang, Adv. Mater., 2013, 25, 5530-5548.

29 X. Yan, F. Wang, B. Zheng and F. Huang, Chem. Soc. Rev., 2012, 41, 6042-6065.

30 D. González-Rodríguez and A. P. Schenning, Chem. Mater., 2010, 23, 310-325.

31 T. Kato, in Handbook of Liquid Crystals, ed. D. Demus, J. W. Goodby, G. W. Gray, H.-W. Spiess and V. Vill, Wiley-VCH, Weinheim, 1998, vol. 2B, pp. 969-979.

32 T. Kato, N. Mizoshita and K. Kanie, Macromol. Rapid Commun., 2001, 22, 797-814.

33 T. Kato, Science, 2002, 295, 2414-2418.

34 C. Tschierske, J. Mater. Chem., 2001, 11, 2647-2671.

35 T. Kato, N. Mizoshita and K. Kishimoto, Angew. Chem., Int. Ed., 2006, 45, 38-68.

36 J.-M. Lehn, Science, 1993, 260, 1762-1764.

37 A. Kohlmeier and D. Janietz, Liq. Cryst., 2007, 34, 65-71.

38 T. Kato and Y. Kamikawa, Handbook of liquid crystals, 2014.

39 S. M. Jansze, A. Martínez-Felipe, J. M. Storey, A. T. Marcelis and C. T. Imrie, Angew. Chem., 2015, 127, 653-656.

40 P. J. Collings, M. Hird and C. Tschierske, Angew. Chem., Int. Ed. Engl., 1997, 36, 2017.

41 D. Janietz and M. Bauer, Macromol. Chem. Phys., 1991, 192, 2635-2640.

42 H. Ahmed, M. Naoum and G. Saad, Liq. Cryst., 2016, 43, 1259-1267.

43 M. Lizu, M. Lutfor, N. Surugau, S. How and S. E. Arshad, Mol. Cryst. Liq. Cryst., 2010, 528, 64-73.

44 W. Cleland and M. M. Kreevoy, Science, 1994, 264, 18871890.

45 A. Martinez-Felipe, A. G. Cook, J. P. Abberley, R. Walker, J. M. Storey and C. T. Imrie, RSC Adv., 2016, 6, 108164108179.

46 A. Martínez-Felipe and C. T. Imrie, J. Mol. Struct., 2015, 1100, 429-437.

47 A. Ghanem and C. Noel, Mol. Cryst. Liq. Cryst., 1987, 150, 447-472.

48 C. Imrie, Liq. Cryst., 1989, 6, 391-396. 